\title{
(3) JIP Stability Studies of Amoxicillin and Gentamicin Injection in Intravenous Infusions
}

\author{
Nyi Mekar Saptarini*, Sohadi Warya, Ayu Dewi Purnama Sari and Anggi \\ Setyarini
}

\author{
Department of Analytical Pharmacy and Medicinal Chemistry, Faculty of Pharmacy, Universitas \\ Padjadjaran, JI Raya Bandung Sumedang km 21 Jatinangor, West Java, Indonesia.
}

\begin{abstract}
Context: Amoxicillinsodium and gentamicin sulfate are commonly antibiotics which used for infection treatment. In Indonesia, injection of antibiotics can be administered concurrently with intravenous infusion. Injection is mixed into the infusion bottle or directly injected into infusion tubing. Before use, mixed of antibiotics and intravenous infusion is usually stored in a refrigerator to maintain stability. Aims: The study was designed to examine the stability of amoxicillin sodium and gentamicin sulfate in intravenous infusions. Methods and Material: Each of Amoxicillin sodium and Gentamicin sulfate was mixed into the ringer's dextrose infusion and ringer's lactate infusion at room temperature $\left(27^{\circ} \mathrm{C}\right)$ and cold temperature $\left(4^{\circ} \mathrm{C}\right)$ for 24 hours. The concentration of antibiotics were measured with Reversed-Phase High Performance Liquid Chromatography for 0, 1 , $2,3,4,5,6$, and 24 hours after antibiotics mixed to intravenous infusions. Results: Quantitative analysis was conducted by RP-HPLC, because this instrument give good separation of antibiotics from other components of intravenous infusion. The values of linearity, accuracy, precision, limit of detection and limit of quantification are fullfilled the criteria for HPLC validation. The stability of Amocixillin sodium influenced by the infusion type, temperature and time, while the stability of Gentamicin sulfate is only influenced by the infusion type. Conclusion: Amoxicillin sodium is more stable in ringer's lactate infusion, whereas Gentamicin sulfate is more stable in ringer's dextrose infusion.
\end{abstract}

Key words: Amoxicillin sodium, Chemical stability, Gentamicin sulfate, Ringer's dextrose, Ringer's lactate.

\section{INTRODUCTION}

Amoxicillin sodium (penicillin derivate) preventing bacteria to form their cell walls. It is used for infection treatment caused by gram-positive and -negative bacteria, including H. influenza, N. gonorrboeae, E. coli., Pneumococci, Streptococci, and certain strain of Staphylococii. Gentamicin sulfate (aminoglycoside derivate) preventing bacteria to synthesize

\begin{tabular}{|c|c|}
\hline \multicolumn{2}{|c|}{ Access this article online } \\
\hline Journal Sponsor & \multirow[b]{2}{*}{$\begin{array}{l}\text { Website: } \\
\text { www.jyoungpharm.org }\end{array}$} \\
\hline \multirow{2}{*}{ www.phcog net } & \\
\hline & $\begin{array}{l}\text { DOI: } \\
\text { 10.5530/jyp.2015.3.16 }\end{array}$ \\
\hline
\end{tabular}

their protein. It is used for infection treatment caused by gram-negative bacteria, including Citrobacter, Enterobacter, E. coli, Klebsiella, Proteus, Serratia, and P. Aeruginosa. ${ }^{1}$

In Indonesian hospitals, antibiotic injection given concurrently with parenteral infusion. Injection is mixed into infusion bottle or directly injected into the infusion tubing. Intravenous antibiotic treatment has advantages, i.e the therapeutic effect acceleration because of drug delivery to the target directly, the total absorption allows more precise dose and more reliable therapy, controlling the drug delivery to modified the therapeutic effect, preventing pain and irritation of certain drugs if given intramuscularly or subcutaneously, preventing irritation or instability drug in

*Address for correspondence:

Mr. Nyi Mekar Saptarini, Department of Analytical Pharmacy and Medicinal Chemistry, Faculty of Pharmacy, UniversitasPadjadjaran, JI Raya Bandung Sumedang km 21 Jatinangor, 45363 West Java, Indonesia. Phone no: +62-8156078248, E-mail: mkrnyi@gmail.com 


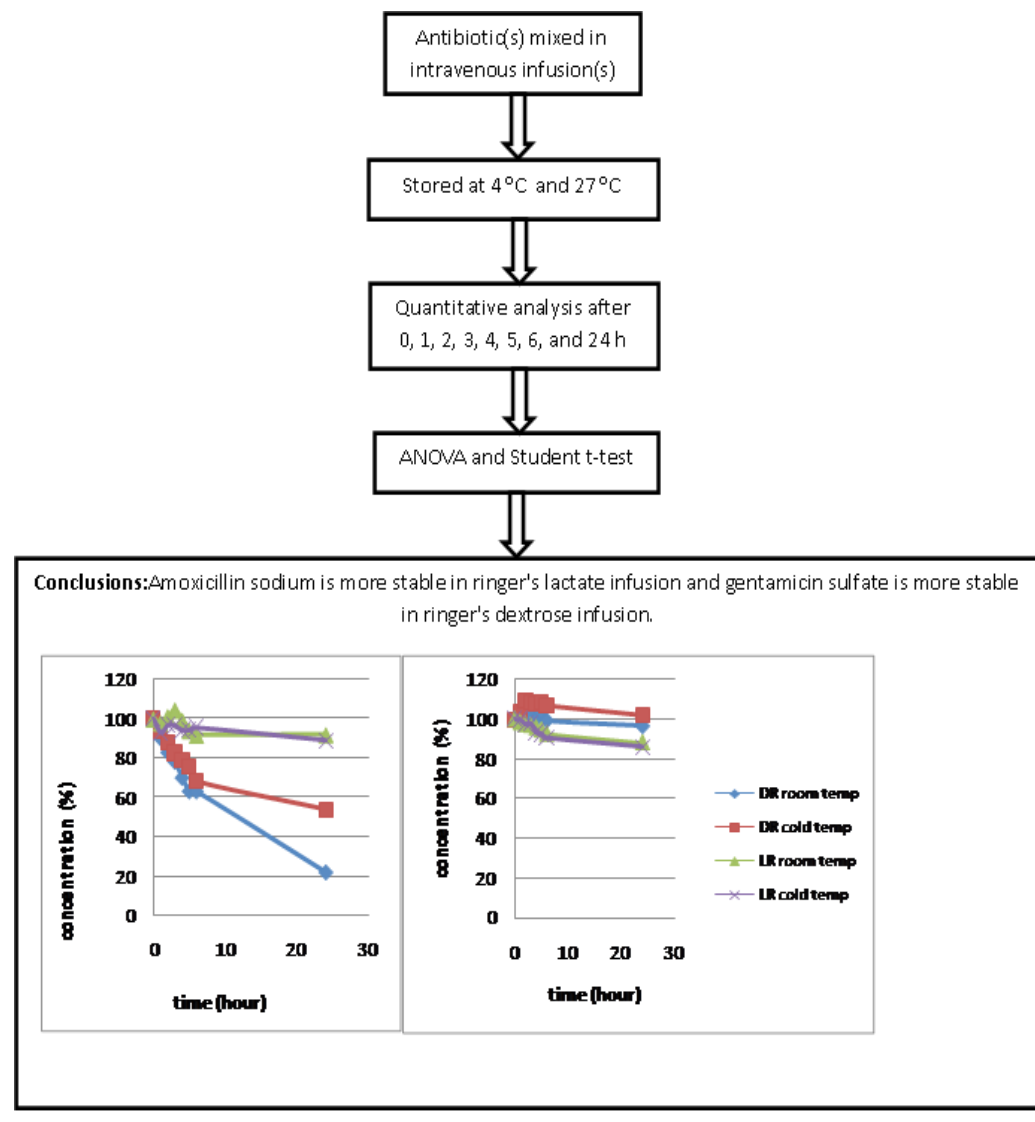

Graphical Abstract

the gastrointestinal tract. ${ }^{2}$ Before use, mixed of antibiotics and intravenous infusion is usually stored in a refrigerator to maintain stability.

The aims of this study is to determine the stability profile of amoxicillin sodium and gentamicin sulfate in ringer's dextrose infusion and ringer's lactate infusion during storage for 24 hours in room temperature $\left(27^{\circ} \mathrm{C}\right)$ and cold temperature $\left(4^{\circ} \mathrm{C}\right)$. The stability profile obtained from the stability of the antibiotic content in infusion, which were determined by High Performance Liquid Chromatography (HPLC).

\section{MATERIALS AND METHODS}

\section{Materials}

The materials are Amoxicillin sodium injection (Meiji), Gentamicin sulfate injection (Indo Farma), sterile aquabidest (IPHA), Trifluoroacetic acid (TFA, Merck), HPLC grade methanol (JT Baker), acid hydrochloride ( $\mathrm{HCl}$, Merck), potassium dihydrogen phosphate (Merck), sodium hydroxide (Merck), ringer's dextrose infusion (Otsuka), and ringer's lactate infusion (Otsuka).

\section{Methods}

\section{HPLC Optimization}

Amoxicillin sodium standard $(10 \mathrm{mg} / \mathrm{L})$ in $0.01 \mathrm{M}$ phospate buffer solution (PBS, pH 5) and acetonitrile (99:1) was injected into C-18 column, with mixture of $0.01 \mathrm{M}$ PBS $(\mathrm{pH} 5)$ and acetonitrile (92:8and 88:12) as mobile phase. Flow rate was $0.8 \mathrm{~mL} / \mathrm{min}$ and detection was $230 \mathrm{~nm}$.

Gentamicin sulfate $(200 \mathrm{mg} / \mathrm{L})$ in $1 \mathrm{M} \mathrm{HCl}$ was injected into C-18 column, with mixture of TFA and methanol (60:40 and 50:50) as mobile phase. Flow rate was $1.0 \mathrm{~mL} /$ min and detection was $257 \mathrm{~nm}$. Parameters observed were resolution, retention time and tailing factor. ${ }^{3}$

\section{HPLC Validation}

Linearity

Linearity is obtained by plotting concentration of antibiotics (amoxicillin sodium and gentamicin sulfate) against area under curve. The concentration of amoxicillin sodium standard was $5,10,25,50$, and $100 \mathrm{mg} / \mathrm{L}$. The concentration of gentamicin sulfate standard was 200 , $300,400,500$ and $600 \mathrm{mg} / \mathrm{L}$. All solutions were millipore- 
filtered and $20 \mu \mathrm{L}$ of each solution was injected into the C-18 column. ${ }^{3}$

\section{Accuracy}

Each of $20 \mu \mathrm{L}$ amoxicillin sodium (10, 50, and 100 $\mathrm{mg} / \mathrm{L})$ and gentamicin sulfate $(300,400$, and $500 \mathrm{mg} / \mathrm{L})$ was injected into the C-18 column. The procedure was repeated three times for each concentration and percentage of recovery was calculated for accuracy. ${ }^{3}$

\section{Precision}

Each of $20 \mu \mathrm{L}$ Amoxicillin sodium $(10 \mathrm{mg} / \mathrm{L})$ and Gentamicin sulfate $(300 \mathrm{mg} / \mathrm{L})$ was injected into the C-18 column. The procedure was repeated 10 times and percentage of RSD was calculated for precision. ${ }^{3}$

Limit of Detection (LOD) and Limit of Quantification (LOQ)

LOD and LOQ were calculated as followed. ${ }^{3}$

$$
\begin{aligned}
& \text { LOD }=\left[\frac{3 S D \quad 3 S D}{\text { slopeslope }}\right] \times 100 \% \\
& L O Q=\left[\frac{10 S D 10 S D}{\text { slopeslope }}\right] \times 100 \%
\end{aligned}
$$

\section{Antibiotics Stability in Intravenous Infusions}

Amoxicillin sodium was dissolved at a final concentration of $125 \mathrm{mg} / \mathrm{mL}$ in aqua pro injection. These solution was added to $100 \mathrm{~mL}$ ringer's dextrose and to $100 \mathrm{~mL}$ ringer's lactate. Samples of the solutions was assayed for chemical stability at $0,1,2,3,4,5,6$, and 24 hours, during storage at room $\left(27^{\circ} \mathrm{C}\right)$ and cold temperature $\left(4^{0} \mathrm{C}\right)$. Samples were taken for initial measurements with HPLC. The mean initial assay value was taken to present $100 \%$ and the $1,2,3,4,5$, 6 , and 24 hours assay results could therefore be expressed as percentages of antibiotic remaining. The entire series of experiments was performed in duplicate.

Gentamicin sulfate was dissolved at a final concentration of $40 \mathrm{mg} / \mathrm{mL}$ in aqua pro injection. The above procedure was repeated with gentamicin sulfate as a substitute for amoxicillin sodium.

\section{Statistical Analysis}

The chemical stability of antibiotics in ringer's dextrose infusion and ringer's lactate infusion were analyzed for the variables of time and temperature. Each data of antibiotic chemical stability were statistically analyzed using two-way analysis of variance.

\section{RESULTS}

\section{HPLC Optimization}

UV spectrum of antibiotic showed one peak at $230 \mathrm{~nm}$ for amoxicillin sodium in PBS:acetonitrile (99:1) and at $257 \mathrm{~nm}$ for gentamicin sulfate in $1 \mathrm{M} \mathrm{HCl}$ (Figure 1).

\section{DISCUSSION}

\section{HPLC Optimization}

Quantitative analysis of amoxicillin sodium and gentamicin sulfate which mixed in the infusion was performed using HPLC instrument. HPLC was chosen because of selective and efficient. ${ }^{4}$ HPLC can be directly carried out the quantitative analysis of antibiotics without extraction of antibiotic from the infusions. It can be done because of the infusion components have no chromophore groups,

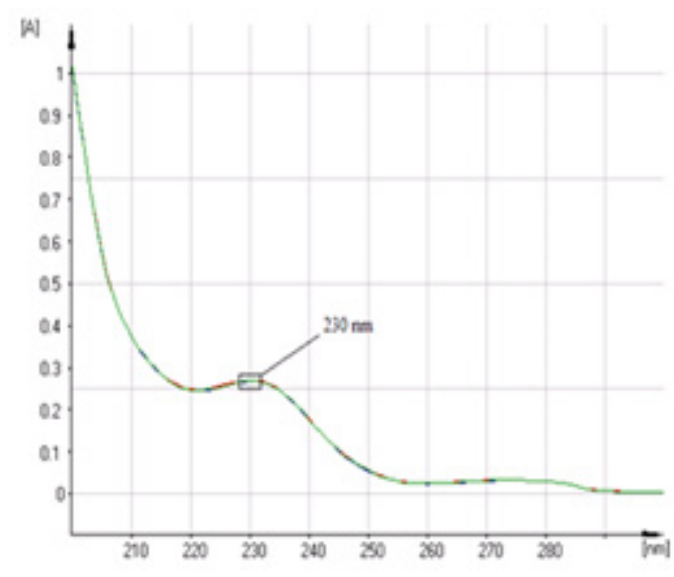

(a)

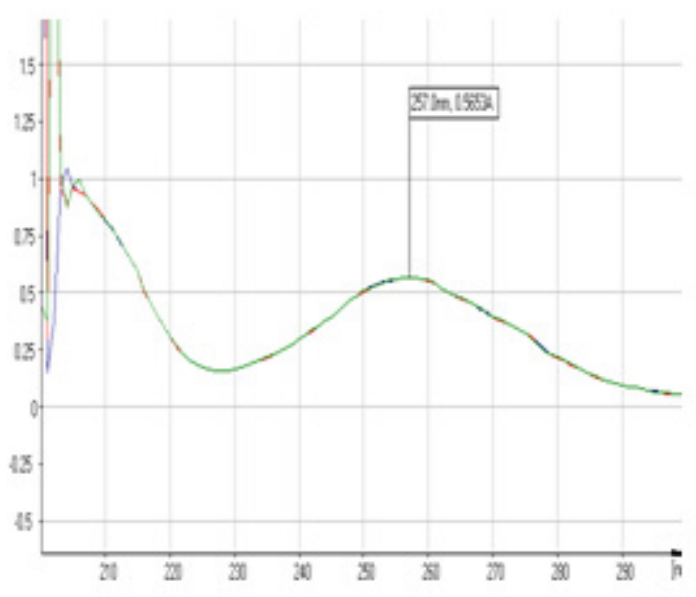

(b)

Figure 1: UV spectrum of (a) Amoxicillin sodium and (b) Gentamicin sulphate 


\begin{tabular}{|c|c|c|c|c|}
\hline \multirow[b]{2}{*}{ Antibiotic } & \multirow[b]{2}{*}{ Mobile phase } & \multicolumn{3}{|c|}{ Parameter } \\
\hline & & Resolution & $\begin{array}{c}\text { Time of retention } \\
(\mathrm{min})\end{array}$ & Tailing factor \\
\hline $\begin{array}{l}\text { Amoxicillin } \\
\text { sodium }\end{array}$ & $\begin{array}{c}\text { PBS:acetonitrile } \\
92: 8 \\
88: 12\end{array}$ & $\begin{array}{l}3.24 \\
4.78\end{array}$ & $\begin{array}{l}4.03 \\
3.00\end{array}$ & $\begin{array}{l}1.78 \\
1.06\end{array}$ \\
\hline $\begin{array}{l}\text { Gentamicin } \\
\text { sulfate }\end{array}$ & $\begin{array}{c}\text { TFA:methanol } \\
60: 40 \\
50: 50\end{array}$ & $\begin{array}{l}11.93 \\
8.86\end{array}$ & $\begin{array}{l}7.47 \\
4.70\end{array}$ & $\begin{array}{l}1.95 \\
1.15\end{array}$ \\
\hline
\end{tabular}

soinfusions will not be detected by UV spectrophotometer as the detector. UV spectrophotometer can be used as a detector, because amoxicillin sodium have chromophores (aromatic compound, carbonyls, carboxylic, and amido), although gentamicin sulfate lack of chromophore. ${ }^{5}$ The UV spectrum of antibiotic showed one peak at $230 \mathrm{~nm}$ for amoxicillin sodium and at $257 \mathrm{~nm}$ for gentamicin sulfate (Figure 1). These peak were elicited by $\neq \rightarrow \neq^{*}$ electronic transition.

Analysis was used the reversed-phase HPLC (RP-HPLC), because of amoxicillin sodium and gentamicin sulfate are soluble in water. ${ }^{5}$ The RP-HPLC has convenience and speed of column equilibration compared to normal-phase HPLC. In RP-HPLC, the hydrophobic stationary phase of silica surface contain silanols and octadecyl chain $\left(\mathrm{C}_{18}\right)$. The $\mathrm{C}_{18}$ has a steric hindrance, so not all silanols on a silica surface can react with analytes. ${ }^{6}$ Amoxicillin sodium has acidic functional groups, i.e. the phenolic group and the carboxylic group. Gentamicin sulfate has acidic functional groups from the hydroxyl groups of sugars and basic functional groups from the amine groups. ${ }^{5}$ Acidic and basic groupsin amoxicillin sodium and gentamicin sulfate are made the ionized or non-ionized form of antibiotics in the solution. The ionized form and degree of ionization will

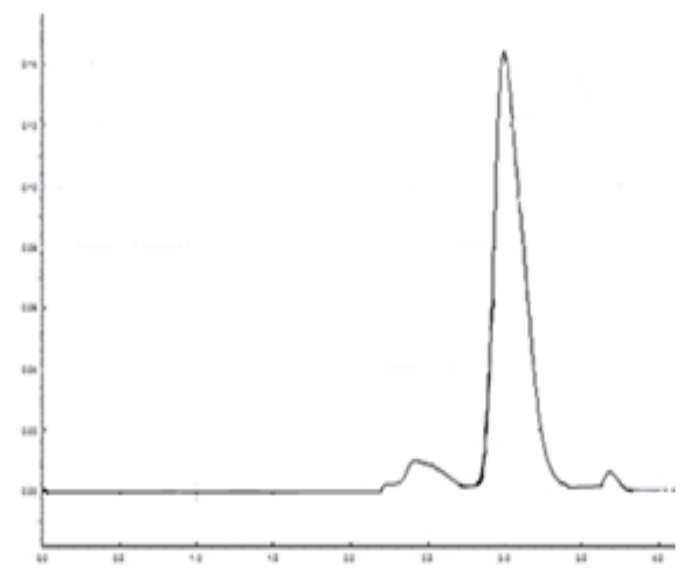

(a) affect the retention of antibiotics in column of RP-HPLC. The coefficient partition of the non-ionized form is better than the ionized form on a hydrophobic stationary phase $\left(\mathrm{C}_{18}\right)$. The acidic and basic anayltes can be separated with a mobile phase containing a buffer solution to control $\mathrm{pH}$ during separation., ${ }^{4,6}$

The goal of most pharmaceutical HPLC analysis is the separation of one or more analytes from other components to obtain quantitative information from each analyte. The degree of separation of two adjacent analyte peaks called resolution. A target of the value of resolution is more than 2.0, because of more robust separation and quantification. ${ }^{4,6}$ All mobile phase which used in HPLC optimization fullfilled the resolution criteria (Table 1).

In RP-HPLC, the retention time of the analyte is depend on polarity or strength of the mobile phase (i.e. the percentage of organic solvent content). Higher content of polar solvents will make smallerof the retention time of the analyte. ${ }^{4} \mathrm{~A}$ mixture of PBS:acetonitrile (88:12) and TFA:methanol (50:50) have a smaller retention time than PBS:acetonitrile (92:8) and TFA:methanol (60:40) (Table 1 and Figure 2).

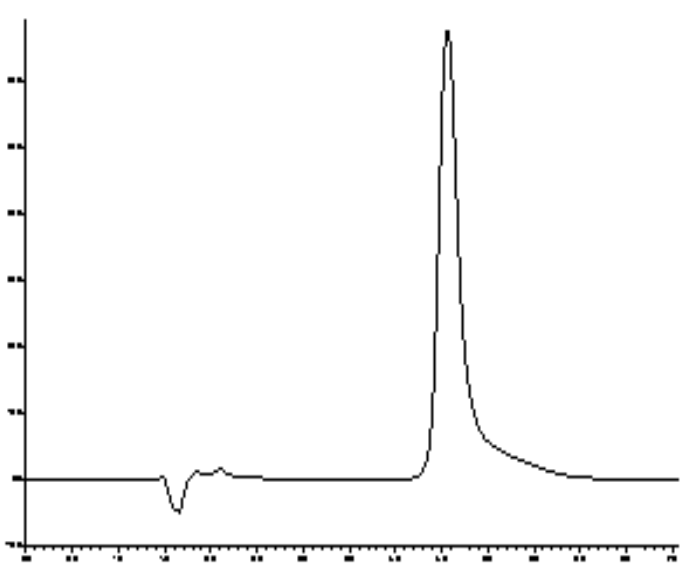

(b)

Figure 2: Chromatogram of mobile phase optimization. (a) PBS: acetonitrile (88:12) for Amoxicillin sodium and (b) TFA:methanol (50:50) for Gentamicin sulphate 
Saptarini, et al.: Stability Studies of Amoxicillin and Gentamicin Injection in Intravenous Infusions

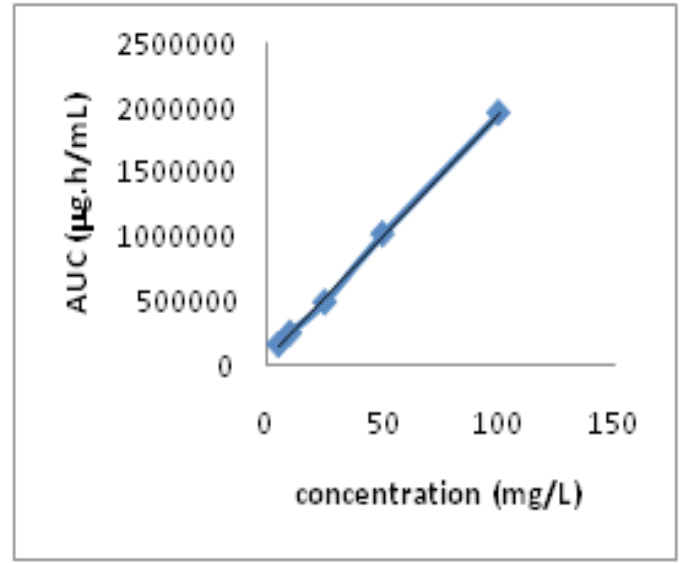

(a)

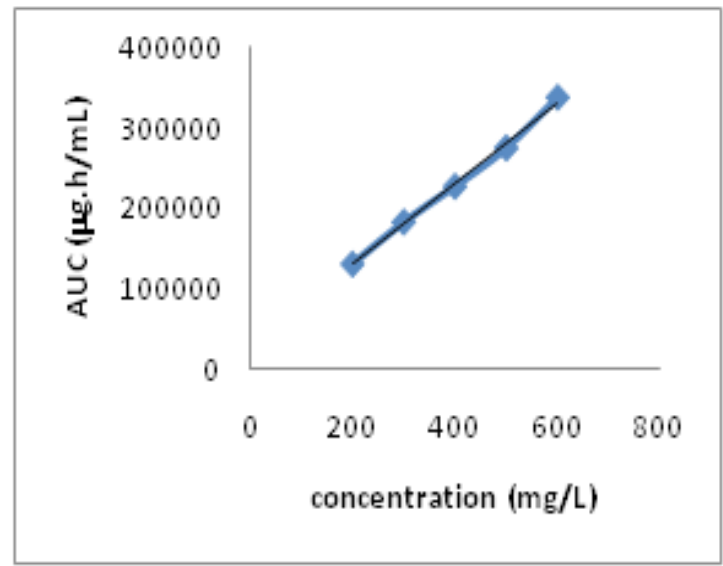

(b)

Figure 3:Linearity of (a) Amoxicillin sodium and (b) Gentamicin sulphate

\begin{tabular}{|ccc|}
\hline Table 2: HPLC Validation & \\
\hline Parameter & Amoxicillin sodium & Gentamicin sulfate \\
\hline Linearity & $\mathrm{y}=19031 \mathrm{x}+52325$ & $\mathrm{y}=0.0501 \mathrm{x}+3.0414$ \\
\hline$\%$ recovery & $101.78-105.79$ & $98.94-101.32$ \\
\hline RSD (\%) & 1.69 & 1.75 \\
\hline LOD (mg/L) & 8.25 & 182.46 \\
\hline LOQ (mg/L) & 27.50 & 608.20 \\
\hline
\end{tabular}

Tailing factors for most peaks is between 0.9 and 1.4, with a value of 1.0 indicating a perfectly symmetrical peak. Tailing is the caused by strong interactions between basic functional groups of the analyte with residual silanol groups on the stationary phase. ${ }^{4,6} \mathrm{~A}$ mixture of PBS: acetonitrile (92: 8) and TFA: methanol (60:40) have a bigger tailing factors than PBS: acetonitrile (88:12) and TFA: methanol (50:50). The lastest mobile phase had better tailing factor, because the values were the closest to 1.00 (Table 1 and Figure 2). Based on resolution, retention time, and tailing factor so the best composition of the mobile phase which selected for this study was a mixture of PBS: acetonitrile (88:12) for amoxicillin sodium and TFA: methanol (50:50) for gentamicin sulfate.

\section{HPLC Validation}

The HPLC validation is done for ensuring that the HPLC procedure performs within acceptable of reliability, accuracy, and precision for its intended purpose. The result of HPLC validation was provided in (Table 2). The linearity studies (Figure 3) indicated that there were good correlation between concentration of antibiotic and detector response for all samples $\left(r^{2}=0.9991\right.$ for amoxicillin sodium and $r^{2}=0.9963$ for gentamicin sulfate). These values fullfilled the linearity criteria, i.e. $\mathrm{R}>0.999 .7,8$
Accuracy showed the closeness in the true value and the actual result obtained. These values were determined from percentage of recovery. Accuracy studies showed that percentage of recovery is $101.78 \%$ to $105.79 \%$ for amoxicillin sodium and $98.94 \%$ to $101.32 \%$ for gentamicin sulfate. These values fullfilled the accuracy criteria, i.e. $98.0 \%$ to $102.0 \%$ with RSD $2.0 \% 0^{7,8}$

Precision indicated the HPLC ability to generate the similar results for multiple preparations. Precision studies showed that RSD value were $1.69 \%$ for amoxicillin sodium and $1.75 \%$ for gentamicin sulfate. These values fullfilled the precision criteria, i.e. RSD not more than $2.00 \% .^{7,8}$

LOD and LOQ were determined from the signal-to-noise ratio, i.e. 3:1 for LOD and 10:1 for LOQ. ${ }^{7,8}$ LOD and LOQ were $8.248 \mathrm{mg} / \mathrm{L}$ and $27.495 \mathrm{mg} / \mathrm{L}$ for amoxicillin sodium and $182.46 \mathrm{mg} / \mathrm{L}$ and $608.20 \mathrm{mg} / \mathrm{L}$ for gentamicin sulfate, respectively. High LOD and LOQ of gentamicin sulfate caused by lack of chromophore. Thisis made the higher concentrations of gentamicin sulfate required in order to be detected by UV spectrophotometer. This results is appropriate with previous study which stated the poor detection of gentamicin sulfate with UV spectrophotometer. The recommendation HPLC detector for gentamicin sulfate is pulsed amperometric detector or equivalent with a gold detector electrode. ${ }^{5}$

\section{Antibiotics Stability in Intravenous Infusions}

Amoxicillin sodium contains not less than $98.0 \%$ and not more than $102.0 \%$ of amoxicillin sodium, calculated on the anhydrous basis. ' Amoxicillin sodium remained stable for 5 hours in ringer's lactate infusion at room and cold temperature. In comparison, a reduction of over

Journal of Young Pharmacists Vol $7 \bullet$ Issue $3 \bullet$ Jul-Sep 2015 


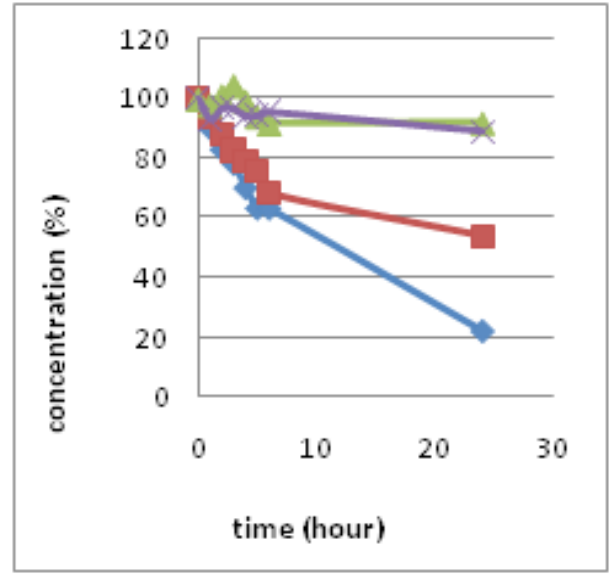

(a)

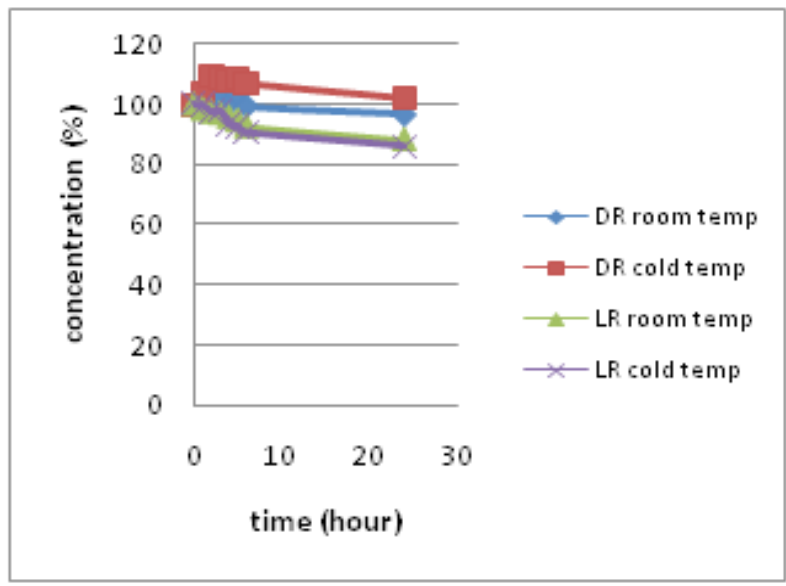

(b)

Figure 4: The graph of chemical stability of (a) Amoxicillin sodium and (b) Gentamicin sulphate

$50 \%$ in chemical stability was detected at 24 hours in ringer's dextrose infusion at cold and room temperature (Figure 4).

Ringer's lactate infusion consists of $\mathrm{NaCl}, \mathrm{KCl}, \mathrm{CaCl}_{2}$, and lactate sodium. Ringer's dextrose infusion consists of $\mathrm{NaCl}$, $\mathrm{KCl}, \mathrm{CaCl}_{2}$, and dextrose monohydrate. Dextrose affected the amoxicillin sodium stability. This results is appropriate to previous study that amoxicillin sodium less stable in $5 \%$ glucose solution..$^{10}$ This results is also appropriate to another study that amoxicillin sodium stability in $\mathrm{NaCl}$ and $\mathrm{KCl}$ solution is same as its stability in the water. The amoxicillin sodium stability in lactate solution is medium. ${ }^{11}$ The amoxicillin sodium degradation also caused by water which made $\beta$-lactam ring dimerization and decomposition. Dimerization (aminolysis) caused by nucleophilic attack of free amino group of the side chain to the $\beta$-lactam carbonyl in the second molecule. ${ }^{12}$

Gentamicin sulfate has a potency equivalent to not less than $590 \mu \mathrm{g} / \mathrm{mg}$, calculated on dried basis. ${ }^{9}$ Gentamicin sulfate remained stable for 24 hours in ringer's dextrose infusion at room and cold temperature. There was reduction of over $12 \%$ in chemical stability was detected at 24 hours in ringer's lactate infusion at room and cold temperature (Figure 4). This results is different from the literature which states that the gentamicin sulfate compatible with solutions containing dextrose, saline, $\mathrm{KCl}$, ringer's, or lactated ringer's. ${ }^{13}$ This is because of gentamicin sulfate was mixed to ringer's lactate for 24 hours, resulting in degradation. The most common degradation products of gentamicin sulfate is gentamin
$\mathrm{C} 1$ and the second product is sisomicin. Sisomicin is an gentamicin sulfate impurities. ${ }^{14}$

\section{Statistical Analysis}

Two-way analysis of variance was performed to analysis the effect of the infusion type, temperature, and time on the chemical stability of Amoxicillin sodium and Gentamicin sulfate in a mixture of antibiotics and infusion solution. The model is the fixed model with two variable of infusion type (ringer's dextrose infusion and ringer's lactate infusion), two variable of storage temperatures (room temperature and cold temperature) and eight variable of storage time $(0,1,2,3,4,5,6$, and 24 hours).

Statistical analysis showed that the chemical stability of amocixillin sodium influenced by the infusion type, temperature and time. While the chemical stability of gentamicin sulfate is only influenced by the infusion type.

\section{CONCLUSION}

Amocixillin sodium stability is influenced by the infusion type, temperature and time, while the stability of Gentamicin sulfate is only influenced by the infusion type. Amoxicillin sodium is more stable in ringer's lactate infusion $(89.13 \%)$ than in the ringer's dextrose infusion $(53.85 \%)$. While Gentamicin sulfate is stable in ringer's dextrose infusion $(102.10 \%)$ than in the ringer's lactate infusion $(96.00 \%)$. 


\section{Highlights of Paper}

- Amoxicillin sodium and Gentamicin sulphate are antibiotics.

- In Indonesia, they are often mixed into intravenous infusion, such as ringer's lactate and ringer's dextrose infusion.

- After research, it was founf that amoxicillin sodium is more stable in ringer's lactate infusion and gentamicin sulfate is more stable in ringer's dextrose infusion.

\section{Author Profile}

- Nyi Mekar Saptarini: presently working as lecturer in the Department of Analytical Pharmacy and Medicinal Chemistry, Faculty of Pharmacy, Univeritas Padjadjaran, Indonesia.

- Sohadi Warya: presently working as lecturer in the Department of Pharmaceutic, Faculty of Pharmacy, Univeritas Padjadjaran, Indonesia.

- Ayu Dewi Purnama Sari: presently is fresh graduate of pharmacist from Faculty of Pharmacy, Univeritas Padjadjaran, Indonesia.

- Anggi Setyarini: presently is fresh graduate of pharmacist from Faculty of Pharmacy, Univeritas Padjadjaran, Indonesia.

\section{REFERENCES}

1. Pharmacists TA. S.o.H.-S. AHFS Drug Information. [cited 2014 April 1st]; Available from: http://www.ahfsdruginformation.com/; 2014.

2. Allen LV, Popovich HC, Ansel. Ansel's Pharmaceutical Dosage Form and Drug Delivery System. Vol. $9^{\text {th }}$ ed. China: Lippincott Williams \& Wilkins; 2011.

3. Agency EM. Validation of Analytical Procedures: Text and Methodology; 1995.

4. Ornaf RM, Dong MW. Key Concepts of HPLC In Pharmaceutical Analysis, in Handbook of Pharmaceutical Analysis by HPLC, Ahuja S, Dong MW, Editors. Elsevier Academic Press: Singapore; 2005.

5. Britain BMAa.R.P.S.o.G. British Pharmacopeia Great Britain: Medicines and Healthcare products Regulatory Agency (MHRA); 2008.

6. Neue UD. Silica Gel and its Derivatization for Liquid Chromatography, In Encyclopedia of Analytical Chemistry Chichester: John Wiley \& Sons, Ltd; 2000.

7. $\mathrm{ICH}$. ICH Guidelines for Method Validation: Q2B Validation of Analytical Procedures: Methodology. 1996 [cited 2015 March 9th]; Available from: http://www.fda.gov/downloads/drugs/ guidancecomplianceregulatoryinformation/guidances/ucm073384. pdf

8. Rasmussen HT. et al. HPLC Method Development, in Handbook of Pharmaceutical Analysis by HPLC, Ahuja S, Dong MW, Editors. Elsevier Academic Press: Singapore; 2005.

9. Pharmacopeia U.S. USP 33 NF 28. Available from: http://www. usp.org/usp-nf/notices/retired-compendial-notices/usp-33-nf-28errata; 2010.

10. McDonald $\mathrm{C}$, et al. The stability of amoxycillin sodium in normal saline and glucose $(5 \%)$ solutions in the liquid and frozen states. Journal of Clinical Pharmacy and Therapeutics 1989; 14(1): 45-52.

11. Cook B, Hill SA, Lynn B. The stability of amoxycillin sodium in intavenous infusion fluids. Journal of Clinical and Hospital Pharmacy 1982; 7(4): 245-50.

12. Connors KA, Amidon GL, Stella VJ. Stabilitas Kimiawi Sediaan Farmasi. Vol. $2^{\text {nd }}$ ed. Semarang: IKIP Semarang Press; 1992.

13. Nentwich PF. Intravenous Therapy: A Comprehensive application of Intravenous Therapy and medication administration Boston. Jones and Bartlett Publishers, Inc;1990.

14. Graham AE, Speicher E, Wiliamson B. Analysis of Gentamicine Sulfate and a Study of Degradation in Dextrose Solution. Journal of Pharmaceutical and Biomedical Analysis 1997; 15(4): 537-43. 